\title{
SUPERVISÃO ESCOLAR E O SUCESSO NA APRENDIZAGEM DAS SÉRIES INICIAIS
}

\author{
Andreia Menegueti \\ Astrogilda Silva de Oliveira ${ }^{2}$ \\ Edilaine da Silva Nazario ${ }^{3}$ \\ Gercina Fabiana Santana Barros ${ }^{4}$ \\ Giselle Carolina de Lima e Silva ${ }^{5}$ \\ Jacques Lenoir Gusmão Moraes ${ }^{6}$ \\ Juliana Almeida de Oliveira ${ }^{7}$ \\ Kassiani Giordani ${ }^{8}$ \\ Marenize de Arruda Freire9
}

RESUMO: A aprendizagem é almejada no planejamento do processo de ensinoaprendizagem, fundamentando-se nos documentos e legislação vigentes na educação básica. a supervisão escolar trabalha junto aos professores na promoção de um processo de ensino-aprendizagem, que possibilite ao aluno construir o seu sucesso na aprendizagem. o objetivo geral deste estudo é discutir as potencialidades do trabalho da supervisão escolar na obtenção do sucesso na aprendizagem dos alunos. este estudo se qualifica como uma pesquisa bibliográfica. o desenvolvimento deste estudo

\footnotetext{
I'Especialista em Educação Física pela Universidade Cândido Mendes - Rio de Janeiro. Graduada em Educação Física Licenciatura pela Universidade Cuiabá - UNIC. Professora efetiva da rede pública municipal de Cuiabá-MT.E-mail: andreiamenegueti978@gmail.com.

${ }^{2}$ Concluído em 1998 pela Universidade de Cuiabá - UNIC o curso de Pedagogia - Licenciatura Plena. Pós-Graduação em 2020 pela Faculdade de Educação São Luís o curso de Educação Especial e Inclusiva. E-mail: astrogildasilvaio@gmail.com.

3 Graduada em Pedagogia pela Universidade Norte do Paraná - UNOPAR, Pós-graduada em Educação Infantil com Ênfase em Alfabetização pelo Instituto Cuiabano de Educação - ICE.

E-mail: Edilaine.nazario@gmail.com.

${ }^{4}$ Graduada em Licenciatura Plena em Pedagogia pela UNIC. Pós-graduada em Educação Infantil e Alfabetização pelo ICEC. E-mail: barrosfabiana2ı2@gmail.com.

${ }^{5}$ Licenciada em Pedagogia pela UNOPAR. Especialista em Educação Infantil com ênfase em letramento pela FACITEP.E-mail: gi.lima3@hotmail.com.

${ }^{6}$ Graduação em licenciatura plena de Educação Física pela Universidade Federal de Mato Grosso. Pós graduação em Educação, motricidade e recreação - ICE - instituto Cuiabano de Educação. E-mail: jacqueslgusmao@yahoo.com.br

${ }^{7}$ Licenciada em Pedagogia pela Universidade de Cuiabá - UNIC. Pós-graduada em Educação Infantil com foco na Educação Especial pela Faculdade Afirmativo. e-mail: almeidajuliana359@gmail.com

${ }^{8}$ Graduada em Pedagogia. Pós-graduada em Educação Infantil pela Faculdade CGESP. E-mail: kassigir8@gmail.com

${ }^{9}$ Graduada em Pedagogia. Pós-graduada em Psicopedagogia pelo Instituto Cuiabano de Educação. Email: marenizefreire@gmail.com.
} 
se aprofunda na compreensão da importância do trabalho da supervisão escolar no contexto educacional, observando a sua influência no desenvolvimento do processo de ensino-aprendizagem da educação básica. As potencialidades da atuação do supervisor escolar na obtenção do sucesso na aprendizagem nas séries iniciais do ensino fundamental consistem no seu trabalho de assessoria, com enfoque na gestão e qualidade do processo pedagógico.

Palavras-chave: Supervisor escolar. Aprendizagem. Sucesso na Aprendizagem. Prática Docente.

\section{INTRODUÇÃO}

A aprendizagem é almejada no planejamento do processo de ensinoaprendizagem, fundamentando-se nos documentos e legislação vigentes na educação básica. $O$ processo de ensino-aprendizagem evidencia os dilemas que envolve a educação brasileira, que influenciam na apresentação do sucesso ou do fracasso na aprendizagem. O diagnóstico psicopedagógico se apresenta como instrumento importante no trabalho de professores e da supervisão escolar, para se trabalhar os pontos necessários do aprendizado dos alunos.

O sucesso na aprendizagem não é realizado sem o reconhecimento das dificuldades dos alunos no processo de ensino-aprendizagem. A definição de estratégias de ensino e de recursos didáticos passam pelos objetivos do processo de ensino-aprendizagem, para a concretização do sucesso de aprendizagem dos alunos. A supervisão escolar trabalha junto aos professores na promoção de um processo de ensino-aprendizagem, que possibilite ao aluno construir o seu sucesso na aprendizagem. Desta maneira, apresenta-se a questão problema que norteou o desenvolvimento deste estudo: Como a Supervisão Escolar trabalha o sucesso na aprendizagem dos alunos?

O objetivo geral deste estudo é discutir as potencialidades do trabalho da Supervisão Escolar na obtenção do sucesso na aprendizagem dos alunos das séries iniciais do ensino fundamental. Os objetivos específicos são os seguintes: contextualizar a Supervisão Escolar e o seu trabalho na educação básica; visualizar os aspectos de aprendizagem no ambiente escolar; e refletir sobre o sucesso na aprendizagem, passando pela abordagem do trabalho da Supervisão Escolar nas instituições de ensino de educação básica.

O desenvolvimento deste estudo se aprofunda na compreensão da importância do trabalho da Supervisão Escolar no contexto educacional, observando a sua influência no desenvolvimento do processo de ensino-aprendizagem da educação básica. As potencialidades dos trabalhos da equipe escolar precisam ser mais debatidas, para se identificar as soluções demandadas aos problemas educacionais. O desenvolvimento desta discussão oportuniza a compreensão do trabalho da Supervisão Escolar junto aos professores e os demais profissionais da educação, para promover o desenvolvimento global dos alunos no processo de 
ensino-aprendizagem, utilizando-se dos conhecimentos pedagógicos, transdisciplinares e interdisciplinares.

Este estudo se qualifica como uma pesquisa bibliográfica, embasada em concepções difundidas em estudos apresentadas em artigos científicos, livros, monografias, dissertações de Mestrado e teses de Doutorado. Inicialmente, contextualizou-se a Supervisão Escolar e o desenvolvimento do seu trabalho na educação básica do país. Sequencialmente, visualizou-se o significado e as representatividades da aprendizagem escolar, observando os seus elementos constitutivos.

\section{Supervisão escolar}

$\mathrm{Na}$ estrutura das instituições de ensino da educação básica, observa-se a atuação do supervisor escolar, promovendo um diálogo entre o setor pedagógico e o setor administrativo. Silva (2013) abordam que a supervisão escolar consiste em um mecanismo de garantia da concretização do planejamento, consequentemente, demandando um profissional capacitado para desempenhar diversas funções presentes na sua atuação. De acordo com a autora, a evolução do processo de ensinoaprendizagem incluiu a demanda pelo supervisor escolar trabalhar com a assessoria ao professor, mediando a relação deste com os seus alunos, definindo uma ação pedagógica relacional para superar os problemas decorrentes no ambiente escolar.

O desenvolvimento de diversas funções exige que o supervisor escolar desenvolva um amplo conjunto de competências cívicas, técnicas e humanas. Maio, Silva e Loureiro (2010) identificam as seguintes competências: interpretativas, capacidade de apreensão do real em diversas vertentes; análise e avaliação, envolve fatos, projetos, atividades e desempenhos; dinamização de formação, envolvendo o profundo conhecimento sobre as carências formativas da organização e estimular ações de formação na aprendizagem colaborativa; e, relacionais, desenvolvendo uma boa capacidade comunicação com os demais e gestão eficaz de conflitos.

A atuação do supervisor escolar envolve um agregado de características que se alinha às demandas funcionais existentes sobre este profissional na escola. Libâneo (2004) identifica que o supervisor escolar deve deter as capacidades de promover a integração, de reunir esforços, liderar, de concatenar o trabalho de diversos profissionais. Gimenes e Martins (20ı0) visualizam a necessidade de uma relação dialética entre o supervisor escolar e todos os demais da equipe de profissionais da instituição de ensino, embasada no desenvolvimento de um bom relacionamento interpessoal e um bom espírito de liderança, que possibilitem a sua atuação e conquista de espaço no ambiente escolar, em uma abordagem crítico participativa.

Leal e Henning (2009) ressaltam que o supervisor escolar não precisa entrar em confronto direto com o professor para ser compreendida a sua opinião, se houver a necessidade. De acordo com estas autoras, a interiorização do agir pedagógico mais qualificado pelo professor, posiciona para si as expectativas do supervisor escolar, sem a imposição de orientações. Essa situação potencializa que um aprendizado ao professor, apoiado pela atuação do professor de sala de aula. 
As mudanças constantes no processo de ensino-aprendizagem e nas práticas pedagógicas pressionam pelo desenvolvimento profissional e de formação do supervisor escolar. Gimenes e Martins (2010) observam que o supervisor escolar é corresponsável pela gestão e qualidade do processo pedagógico, inclusive apresentando influências diretas e indiretas no trabalho da equipe dos professores em sala de aula. Os referidos autores contemplam que o supervisor escolar anseia por implementar as teorias apreendidas em sua formação permanente, mas se defronta com dificuldades na maioria das situações, pois a maior parte do seu tempo de trabalho é direcionado para a resolução de problemas burocráticos. Os problemas burocráticos desviam o seu foco de trabalho das ações de articulação e mediação do desenvolvimento do processo de ensino-aprendizagem.

Paro (20II) visualiza que a atuação do supervisor escolar demanda a superação da tradicional redução de suas funções aos aspectos burocráticos, para o enfoque no efetivo entrosamento com a coordenação pedagógica da escola e para a valorização das funções de assessoria, apoio e aperfeiçoamento da prática docente nas escolas. Este direcionamento dos trabalhos do supervisor escolar é fundamental para o desenvolvimento da qualidade na supervisão, para além do domínio da sala de aula.

Alarcão e Roldão (2008) fundamentam que a qualidade da supervisão escolar se encontra alinhada aos critérios de promoção da capacidade de reflexão crítica, observando a ação profissional na abordagem conceitual da formação do professor reflexivo. Maio, Silva e Loureiro (2010) salientam que a supervisão escolar não se restringe ao domínio de sala de aula, pois deve-se defrontar com os seguintes fatores: a formação e o desenvolvimento profissional dos supervisores, que influencia no desenvolvimento e aprendizagem dos alunos; e, o desenvolvimento e aprendizagem organizacional, influenciando na vida das escolas.

A relação entre o supervisor escolar e o professor é agregadora na construção de um processo de ensino-aprendizagem, que se embasa no desenvolvimento de uma aprendizagem significativa. Os conflitos entre estes profissionais favorecem o fracasso na aprendizagem dos alunos nas instituições de ensino de educação básica. A aprendizagem é uma construção presente no desenvolvimento do aluno no ambiente educativo, impulsionada pelas práticas pedagógicas aplicadas nas estratégias de ensino.

\section{A aprendizagem no contexto escolar}

A aprendizagem se desenvolve por meio de um processo, em que os conhecimentos são apreendidos por meio de estratégias de ensino articuladas com os recursos didáticos, embasando-se em diversas práticas pedagógicas. A tipologia de aprendizagem é apresentada em duas formas, a mecânica e a significativa.

A aprendizagem se constitui um importante componente de construção do indivíduo e de sua formação, passando pelo seu desenvolvimento no ambiente escolar. Gaspar et al. (2020) ressaltam que a escola fornece um contexto de socialização em que os alunos são capazes de aprender um conjunto de competências, parte delas associadas ao desempenho e sucesso escolares, e ainda se constitui um 
ambiente exclusivo em que o bem-estar social e emocional dos alunos pode ser desenvolvido.

No ambiente escolar, a aprendizagem dos alunos é trabalhada diariamente, buscando-se identificar formas organizadas e sistematizadas para desenvolvê-la no processo de ensino-aprendizagem. Neves (2019) visualiza que o aprendizado proporciona a evolução do indivíduo e do seu próprio desejo ou demanda por aprender, com abrangência de experiências educativas, de construção e expressão de sentidos referentes às aprendizagens construídas.

Souza (2018) aborda que a aprendizagem envolve uma variedade de processos pelos quais os alunos aprendem, independentemente da sua origem ou da forma de ocorrência. A referida autora contempla que não existe maneira correta ou errada de aquisição de conhecimentos, mas correm diferentes formas relacionadas ao resultado almejado, a forma de trabalho, as relações que se deseja desenvolver com o mundo, e entre outros aspectos. Esta constatação demonstra a existência de uma liberdade para se trabalhar os processos e elementos que envolvem as estratégias por meio das práticas pedagógicas, que podem ser continuamente renovadas.

Brooks e Brooks (1999) caracterizam a aprendizagem como dinâmica, complexa e desafiadora da percepção linear e simples das coisas. Souza (2018) indica que o elemento construído como conhecimento na aprendizagem é dependente da compreensão particular em relação ao mundo. O conhecimento escolar deve ser contextualizado, para facilitar a apreensão e desenvolvimento dele na aprendizagem do aluno.

O desenvolvimento da aprendizagem envolve processos que passam por mudanças contínuas, inclusive no ato de ensinar, para atendimento das demandas de aprendizado dos alunos na educação básica. De acordo com Zerbato e Mendes (2018) salientam que as mudanças no ato de ensinar envolvem um trabalho de execução difícil, demanda-se uma rede de profissionais de apoio, recursos suficientes, formação e outros componentes necessários para a concretização de um ensino de qualidade.

Gonçalves (2006) complementa que a prática pedagógica é um desafio no cotidiano escolar, pois demanda conhecimentos diversificados dos professores, e assim mais informações sobre o aluno e as demandas concretas de aprendizagem. Neves (2019) aborda que a relação pedagógica é fomentada por um conjunto de percepções e de representações das pessoas que convivem no espaço de aprendizagem e em um determinado momento. As práticas pedagógicas se desenvolvem por meio destas relações no ambiente escolar.

O desenho universal para a aprendizagem se utiliza de conhecimentos científicos para direcionarem o planejamento do processo de ensino-aprendizagem, definindo-se as estratégias de ensino, metodologias, recursos didáticos e demais componentes. De acordo com Nelson (2013), o desenho universal para a aprendizagem se constitui pelos seguintes princípios: a aprendizagem possui relação com os componentes emocionais e biológicos do indivíduo; a essencialidade de experiências significativas aos alunos; a importância das emoções na motivação do aluno; a importância do ambiente; a aprendizagem deve ser significativa para o 
aluno; cada indivíduo é único; a aprendizagem é aprimorada com desafios e inibida com ameaças.

A construção da aprendizagem passa pela definição e implementação de estratégias articuladas e sistematizadas em contexto de planejamento do processo de ensino-aprendizagem. Boruchovitch (2007) destaca dois tipos de estratégias de aprendizagem: a cognitiva, que se relaciona à execução de atividades que promovem o conhecimento, por meio de uma apropriação baseada na organização e na memória; e metacognitiva, que se relaciona ao aprender a aprender, identificando-se a melhor forma de resolver a situação-problema. Estas estratégias podem ser aplicadas de uma forma geral na aprendizagem escolar, sendo necessário o alinhamento com os objetivos do processo de ensino-aprendizagem.

Darroz, Travisan e Rosa (2018) destacam que a forma como os alunos se estrutura para aprender se constitui entre os fatores mais decisivos na aprendizagem e no sucesso escolar. Os referidos autores complementam que os professores devem considerar na prática pedagógica a forma como os alunos aprendem em sala de aula, buscando-se caminhos de qualificação do processo de aprendizagem embasadas na revisão e adoção de novas concepções de aprender. Neste contexto de desenvolvimento da aprendizagem escolar, a educação musical se apresenta como uma estratégia de ensino aplicada no processo de ensino-aprendizagem da educação básica.

As variações entre as formas de aprendizagem são constantes no desenvolvimento do processo de ensino-aprendizagem. Braathen (2012) define a aprendizagem mecânica como um processo que consiste na incorporação de um conhecimento novo de forma arbitraria, sem espaços de livre interpretação ao aluno. Segundo este autor, a aprendizagem significativa consiste em um processo de incorporação de conhecimento novo na estrutura cognitiva do aluno, pode estar associado ao conhecimento prévio, relacionado e relevante, presente na estrutura cognitiva dele. No processo de aprendizagem, a relação entre professor e aluno é base para sua construção, utilizando-se principalmente da comunicação.

Brait et al. (2010) destacam que as relações entre professor e aluno contemplam intenções e interesses, com esta relação se constituindo a base das consequências, pois a educação é uma das fontes mais importantes na formação comportamental e fator agregador de valores nos membros da sociedade. Os referidos autores caracterizam a interação entre ensino e aprendizagem pela seleção, preparação, organização e sistematização didática dos conteúdos para facilitar o desenvolvimento do aprendizado dos alunos. Esta interação é aprimorada pelo desenvolvimento de práticas pedagógicas construtivas e significativas na formação dos alunos.

As práticas pedagógicas se desenvolvem dentro do contexto da relação professor e aluno, para a construção da aprendizagem escolar. Gomes et al. (2006) enfatizam que a prática pedagógica deve deter uma dinâmica própria, que lhe possibilite a realização do pensamento reflexivo, conduza à uma visão política de cidadania e seja integradora de arte, cultura e valores, constituindo uma interação que recupere a autonomia dos sujeitos e uma ocupação significativa dos seus espaços no 
mundo. A prática pedagógica não pode ser padronizada, pois deve contemplar diversos fatores que variam nos contextos de aprendizagem em sala de aula.

Lourenço e Paiva (2010) ressaltam que as tarefas e as atividades vivenciadas no processo de ensino-aprendizagem são associadas aos processos cognitivos, definidos e detentores da capacidade de atenção, de concentração, de processamento de informações, de raciocínios e de resolução de problemas. A prática pedagógica deve ser pensada para fomentar um aprender interessante e prazeroso, em um contexto em que se visualiza o aprender como se fosse somente uma obrigação.

Brait et al. (2010) salientam que o aprender se constitui mais interessante a partir do momento em que o aluno se sente parte envolvido pelas atitudes e métodos de motivação no processo de ensino-aprendizagem. De acordo com estes autores, o prazer no aprender não é uma atividade espontânea, pois os professores precisam estimular a curiosidade no aluno e o interesse dele em cultivar sempre novos conhecimentos no processo de ensino-aprendizagem.

Lourenço e Paiva (2010) ressaltam que a aprendizagem se apresenta influenciada pelos seguintes fatores: inteligência, incentivo, motivação e hereditariedade. Os referidos autores observam que os fatores essenciais para apreensão das novas informações adquiridas e processadas pelo aluno são o estímulo, o impulso, o reforço e a resposta. No planejamento do processo de ensinoaprendizagem, o professor deve considerar estes fatores para se trabalhar as práticas pedagógicas demandas para o desenvolvimento da aprendizagem significativa dos alunos.

Os alunos podem apresentar dificuldades de aprendizagem, que devem ser diagnosticadas e trabalhadas adequadamente pelo professor no processo de ensinoaprendizagem. Considerando o processo construtivo-interpretativo, Rossato e Martínez (2013) identificam dois caminhos para superação destas dificuldades de aprendizagem: a formação do sujeito no confronto com o outro; e, a mudança na personalidade fomentada pelas reconfigurações subjetivas e o impacto na produção qualitativa de significados subjetivos. A superação das dificuldades, abre-se caminho para o sucesso na aprendizagem escolar, em um processo apoiado e orientado pelo supervisor escolar no ambiente educativo.

\section{$3 \mathrm{O}$ sucesso na aprendizagem perante a supervisão escolar}

O desenvolvimento da aprendizagem passa pelo trabalho do supervisor escolar, inclusive os seus resultados, contemplando sucesso ou fracasso. Ferreira (2019) observa que o supervisor escolar deve acompanhar a prática docente, com objetivo de tornar os professores os supervisores de suas próprias práticas, utilizando-se da interação, diálogo e intercâmbio de experiências. $\mathrm{O}$ referido autor destaca que a atuação do supervisor de proporcionar condições para os objetivos do processo de ensino-aprendizagem sejam alcançados, alinhando uma busca contínua de aprimoramento de seus conhecimentos teóricos e práticos, de forma diferenciada e inovadora.

O sucesso na aprendizagem é almejado em todo o processo de ensino de ensino-aprendizagem, por meio do desenvolvimento de diversas estratégias de 
ensino articuladas com os recursos didáticos e com as práticas pedagógicas. Maio, Silva e Loureiro (2010) enfatizam que o sucesso educativo dos alunos são demandas sociais, que não se resignam com as rotinas. Os referidos salientam que os aspectos do ensino e as finalidades da escola demandam uma atitude intencional, em todos os seus processos e ações. Esta atitude intencional é apresentada no planejamento do processo de ensino-aprendizagem, embasando-se em diretrizes definidas para a aprendizagem significativa dos alunos

Silva (2013) salientam que a escola se constitui um espaço de formação humana, trabalhando com o desenvolvimento de múltiplas potencialidades dos alunos, para direcioná-los na construção de melhores formas de ser, fazer e conviver em sociedade. A referida autora enfatiza que o supervisor escolar se evidencia como um profissional que contribui diretamente para o sucesso da aprendizagem escolar, por meio de suas observações e intervenções junto à equipe de profissionais da escola, na busca do desenvolvimento da totalidade na instituição. Este profissional visualiza a qualidade de ensino inserida nos objetivos do processo de ensino-aprendizagem.

Paro (20II) compreende que a abordagem da qualidade de ensino envolve observar a educação como prática democrática, considerando perspectivas de transformação da escola atual, utilizando-se de análises e propostas que superem a relação pedagógica conservadora empregada nos diversos sistemas públicos de ensino do país. Maio, Silva e Loureiro (2010) observam que a escola contemporânea deve assumir uma identidade própria e embasada nos elementos de sua comunidade educativa, em resposta à realidade multifacetada.

Lourenço e Paiva (2010) mencionam a existência de áreas curriculares com conteúdo programático ajustado para cada ano escolar, proporcionando dificuldades na prática docente, principalmente no desenvolvimento de uma temática em uma abordagem que todos sejam enquadrados. Os referidos autores enfatizam que estes conteúdos devem ser planificados e organizados em consonância com os interesses concretos dos alunos, observando a interdisciplinaridade e a fusão destes conteúdos.

O sucesso na aprendizagem é visualizado mediante diversas interpretações pelos gestores, especialistas e profissionais de educação, mas sempre observando os seus elementos e suas respectivas características e ações no contexto do processo de ensino-aprendizagem. Ferreira (2019) observa que a avaliação de desempenho se apresenta como uma forma coletiva de supervisores e professores analisarem o trabalho desenvolvido e, sequencialmente, promover a busca por melhorias na garantia do sucesso na aprendizagem. No sucesso da aprendizagem, a reflexão e a criticidade do supervisor escolar e do professor fortalecem o planejamento escolar para o sucesso na aprendizagem.

\section{CONSIDERAÇÕES FINAIS}

O supervisor escolar possui um importante papel no desenvolvimento do processo de ensino-aprendizagem, contemplando diversas atribuições que se congregam para garantir a aprendizagem. O desenvolvimento destas atribuições demanda uma capacitação interdisciplinar e ampla, pois o trabalho do supervisor envolve várias relações na organização, principalmente com os professores. As 
competências do supervisor escolar são aplicadas na função de assessoria ao professor no desenvolvimento do processo de ensino-aprendizagem. As atribuições burocráticas ocupam um tempo considerável no trabalho dos supervisores escolares nas escolas, e prejudica a sua dedicação nos trabalhos de assessoria.

O trabalho do supervisor escolar possui o enfoque na gestão e qualidade do processo pedagógico, promovendo a interiorização da prática pedagógica no processo de ensino-aprendizagem. Este trabalho envolve uma dialética do supervisor escolar com o professor e demais profissionais da escola, e envolvendo também um diálogo com os familiares dos alunos. O desenvolvimento do bom relacionamento interpessoal é fundamental na concretização dos objetivos do trabalho do supervisor escolar. A qualidade do processo de ensino-aprendizagem passa pela promoção da capacidade de reflexão crítica, observando a ação profissional na abordagem conceitual da formação do professor reflexivo.

A aprendizagem se desenvolve em dois formatos, mecânica e significativa. As relações entre professor e aluno envolve intenções e interesses, que devem ser reconhecidos pelo supervisor escolar. Há uma distinção entre os processos de ensino e de aprendizagem, mas ambos dialogam entre si. A prática pedagógica deve deter uma dinâmica própria, sendo capaz de integrar os diversos componentes do processo de ensino-aprendizagem.

As tarefas e as atividades escolares trabalham os processos cognitivos, que devem ser considerados no planejamento do processo de ensino-aprendizagem pelo professor e pelo supervisor escolar. As dificuldades de aprendizagem são decorrentes no processo de ensino-aprendizagem, demandando o reconhecimento dos processos cognitivos e da subjetividade dos envolvidos.

A obtenção do sucesso na aprendizagem é desafiadora aos professores, passando pelo trabalho do supervisor escolar. A atitude intencional dos envolvidos é essencial na concretização do sucesso na aprendizagem escolar. $O$ sucesso na aprendizagem contempla um espaço de desenvolvimento de múltiplas potencialidades dos alunos, observando a qualidade e a gestão do processo pedagógico em sala de aula. A atuação do supervisor escolar é abrangente na instituição de ensino, pois não se restringe ao domínio da sala de aula, utilizando-se de observações, orientações e intervenções no processo de ensino-aprendizagem. A compreensão do sucesso na aprendizagem passa pela avaliação desempenho escolar, realizada pelo professor e supervisor escolar.

Desta maneira, conclui-se que as potencialidades da atuação do supervisor escolar na obtenção do sucesso na aprendizagem consistem no seu trabalho de assessoria, com enfoque na gestão e qualidade do processo pedagógico nas séries iniciais do ensino fundamental. Neste contexto, a capacitação e o diálogo são instrumentos de desenvolvimento do trabalho do supervisor escolar, direcionando as ações para o sucesso na aprendizagem. A reflexão possibilita a promoção da criticidade no planejamento do processo pedagógico, definindo as práticas pedagógicas pelo professor, orientado pelo supervisor escolar.

Considerada esta abordagem, sugere-se o desenvolvimento de um estudo sobre a formação do supervisor escolar. A abordagem deste estudo se constitui agregador ao aprofundamento deste estudo. 


\section{REFERÊNCIAS}

ALARCÃO, Isabel, ROLDÃO, Maria do Céu. Supervisão. Um contexto de desenvolvimento profissional dos professores. Mangualde: Edições Pedago, 2008.

BORUCHOVITCH, Evely. Aprender a aprender: propostas de intervenção em estratégias de aprendizagem. ETD - Educação Temática Digital, v. 8, n. 2, p. 156-167, 2007. Disponível em: 〈http://repositorio.unicamp.br/handle/REPOSIP/ II8996〉. Acesso em 24 de outubro de 202r.

BRAATHEN, Per Christian. Aprendizagem mecânica e aprendizagem significativa no processo de ensino-aprendizagem de Química. Revista eixo, v. I, n. I, p. 63-69, 2012. Disponível em: <http://revistaeixo.ifb.edu.br/index.php/ RevistaEixo/article/view/53>. Acesso em 24 de outubro de 202I.

BRAIT, Lílian Ferreira Rodrigues et al. A relação professor/aluno no processo de ensino e aprendizagem. Itinerarius Reflectionis, v. 6, n. I, 2010. Disponível em: 〈https://www.revistas.ufg.br/rir/article/view/40868〉. Acesso em 24 de outubro de 2021.

BROOKS, Jacqueline Grennon; BROOKS, Martin G. In search of understanding: The case for constructivist classrooms. Alexandria: Association for Supervision and Curriculum Development, 1999. 137 p.

FERREIRA, Júnio Fábio. A relação entre professor e supervisor escolar para o sucesso do processo ensino aprendizagem. Humanidades e Tecnologia (FINOM), v. I6, n. I, p. 64-78, 2019. Disponível em: <http://revistas.icesp.br/ index.php/FINOM_Humanidade_Tecnologia/article/view/656>. Acesso em 24 de outubro de 2021.

GASPAR, Tania et al. Ecossistemas de aprendizagem e bem-estar: factores que influenciam o sucesso escolar. Psicologia, Saúde and Doenças, v. 2I, n. 02, p. 462-48I, 2020. Disponível em: 〈https://repositorio.ul.pt/handle/ro45I/44412 >. Acesso em 24 de outubro de 202I.

GIMENES, Oliria Mendes; MARTINS, Adriana Auxiliadora. Supervisão escolar: entre os ditames da legislação e os desafios da prática pedagógica. Revista da Católica, p. 380-39o, 2010. Disponível em: 〈http://www.oliriagimenes.com.br/ site/wp-content/uploads/2019/o9/supervisao_escolar_entre_os_ditames_da_ legislacao_e_os_desafios_da_praticajan-junzoı_CATOLICA.pdf $>$. Acesso em 24 de outubro de 2021. 
GOMES, Annatália Meneses de Amorim et al. Os saberes e o fazer pedagógico: uma integração entre teoria e prática. Educar em Revista, n. 28, p. 231-246, 2006. Disponível em: <https://www.scielo.br/scielo.php?pid=Soro4-406020060o $0200015 \&$ script $=$ sci_arttext $\&$ tlng=pt $>$. Acesso em 24 de outubro de 202I.

GONÇALVES, Aline Kelly Scalco. Estratégias pedagógicas inclusivas para crianças com paralisia cerebral na educação infantil. 2006.136f. Dissertação de Mestrado. Universidade Federal de São Carlos, São Carlos/SP.

LEAL, Adriana Bergold; HENNING, Paula Corrêa. Do exame da supervisão ao autoexame dos professores: estratégias de regulação do trabalho docente na supervisão escolar. Currículo sem Fronteiras, v.9, n.I, pp.251-266, Jan/Jun 2009. Disponível em: 〈http://cienciasecognicao.org/revista/index.php/cec/ article/view/ 313>. Acesso em 24 de outubro de 2021.

LIBÂNEO, José Carlos. Organização e gestão da escola: teoria e prática. 5.ed. revista e ampliada. Goiânia: Editora Alternativa, 2004.

LOURENÇO, Abílio Afonso; PAIVA, Maria Olímpia Almeida. A motivação escolar e o processo de aprendizagem. Ciências \& Cognição, v. 15, n. 2, 2010. Disponível em: < http://repositorio.furg.br/handle/I/I671 >. Acesso em 24 de outubro de 202I.

MAIO, Natividade; SILVA, Helena Santos; LOUREIRO, Armando. A supervisão: funções e competências do supervisor. Eduser-Revista de Educação, v. 2, n. I, 2010. Disponível em: 〈https://www.eduser.ipb.pt/index.php/eduser/article/ view/rg〉. Acesso em 24 de outubro de 202I.

NELSON, Loui Lord. Design and deliver: Planning and teaching using universal design for learning. Baltimore: Brookes Publishing, 2013.

NEVES, João Paulo Santos. Avaliação educacional e aprendizagem escolar. Jornal de Políticas Educacionais, v. 13, 2019. Disponível em: 〈https:// revistas.ufpr.br/jpe/article/view/67788>. Acesso em 24 de outubro de 2021.

PARO, Vitor Henrique. Progressão continuada, supervisão escolar e avaliação externa: implicações para a qualidade do ensino. Revista Brasileira de Educação, v. I6, n. 48, p. 695-716, 20II. Disponível em: 〈https://www.scielo.br/ scielo.php?pid=SI413-24782011000300009\&script=sci_arttext $>$ Acesso em 24 de outubro de 2021.

ROSSATO, Maristela; MARTÍNEZ, Albertina Mitjáns. Desenvolvimento da subjetividade: análise de histórias de superação das dificuldades de aprendizagem. Psicologia Escolar e Educacional, v. 17, n. 2, p. 289-298, 2013. 
Disponível em: 〈https://www.redalyc.org/pdf/2823/282329398oIr.pdf $\rangle$. Acesso em 24 de outubro de 2021.

SILVA, Antonia Maria Cardoso. A supervisão escolar $\mathbf{e}$ as intervenções do supervisor no processo de ensino e aprendizagem. 2013. 122f. Dissertação (Mestrado em Ciências da Educação), Universidade Lusófona de Humanidades e Tecnologias, Lisboa, 2013.

SOUZA, Larissa Negris. Arquitetura escolar, parâmetros de projeto e modalidades de aprendizagem. 2018. I8gf. Dissertação (Mestrado em Arquitetura, Tecnologia e Cidade), Universidade de Campinas, Campinas, 2018.

ZERBATO, Ana Paula; MENDES, Enicéia Gonçalves. Desenho universal para a aprendizagem como estratégia de inclusão escolar. Educação Unisinos, v. 22, n. 2, p. I47-155, 2018. Disponível em:< https://www.redalyc.org/jatsRepo/4496/ 449657611004/449657611004.pdf >. Acesso em 24 de outubro de 2021. 